\title{
Analisis Pengaruh Content Marketing terhadap Customer Engagement (Studi Pada Instagram @bloomcoffeejkt)
}

\author{
Heru Chandra Litmanen, Wulan Purnama Sari \\ herucl13@gmail.com,wulanp@fikom.untar.ac.id
}

Fakultas Ilmu Komunikasi Universitas Tarumanagara

\begin{abstract}
In the modern digital era like today, it cannot be denied that technological developments have developed very rapidly and cannot be avoided. This also affects the world of marketing through social media. The presence of the concept of digital marketing makes it easier for marketers to carry out marketing activities and interact with their audiences. Therefore, this study aims to determine the concept of content marketing carried out by Bloom Coffee to increase customer engagement through Instagram media. Data is distributed and collected by survey method to respondents. Measurement of the questionnaire scale used is a Likert scale. The sample used in this studywere followers of Instagram @bloomcoffeejktwith a total of 100 respondents. The analytical method used is simple linear regression analysis. Researchers use Ms. Excel and IBM Statistics 22 (SPSS version 22) for processing and analyzing sample data. From the results of simple linear regression analysis, it produces a hypothesis which indicates that content marketing has a significant effect on customer engagement. The result of the hypothesis in the t test is a significant value of Content Marketing 0,000 or less than 0.05. The conclusion from this research is that the application of Content Marketing indicators in@bloomcoffeejkt is good and correct for Customer Engagement.However, @bloomcoffeejkt must always conduct a review or review periodically to ensure that there are no errors and no decline occurs.
\end{abstract}

Keywords: content marketing, customer engagement, social media

\begin{abstract}
Abstrak
Pada era digital modern seperti sekarang ini, tidak dapat dipungkiri bahwa perkembangan teknologi telah berkembang dengan sangat pesat dan tidak dapat dihindari. Hal ini juga mempengaruhi dunia pemasaran melalui media sosial. Hadirnya konsep digital marketing mempermudah pemasar untuk melakukan kegiatan pemasaran dan berinteraksi dengan khalayaknya. Oleh karena itu, penelitian ini bertujuan untuk mengetahui konsep Content Marketing yang dilakukan oleh Bloom Coffee untuk meningkatkan customer engagement melalui media Instagram. Data disebar dan dikumpulkan dengan metode survei kepada responden. Pengukuran skala kuesioner yang digunakan adalah skala Likert. Sampel yang digunakan dalam penelitian ini adalah followers instagram @bloomcoffeejkt dengan total 100 responden. Metode analisis yang digunakan adalah analisis regresi linear sederhana. Peneliti menggunakan Ms. Excel dan IBM Statistics 22 (SPSS versi 22) untuk mengolah dan menganalisis sampel data. Dari hasil analisis regresi linear sederhana, menghasilkan satu hipotesis yang menunjukkan bahwa Content Marketing berpengaruh secara signifikan terhadap Customer Engagement. Hasil hipotesis pada uji t yaitu nilai signifikan Content Marketing 0,000 atau lebih kecil dari 0,05. Kesimpulan yang didapat dari penelitian ini yaitu penerapan indikator-indikator Content Marketing dalam @bloomcoffeejkt sudah baik dan benar terhadap CustomerEngagement. Namun@bloomcoffeejkt harus selalu melakukan peninjauan atau review secara berkala untuk memastikan tidak terdapat kesalahan dan tidak terjadi penurunan.
\end{abstract}


Heru Chandra Litmanen, Wulan Purnama Sari: Analisis Pengaruh Content Marketing terhadap Customer Engagement (Studi Pada Instagram @bloomcoffeejkt)

Kata Kunci: Content Marketing, Customer Engagement, Social Media

\section{Pendahuluan}

Industri bisnis dalam bidang coffee shop dinilai memiliki prospek yang cukup baik dan menjanjikan sehingga hal ini mendorong para wiraswasta untuk membuka dan menjalankan usaha-usaha baru sehingga persaingan di dalam dunia coffee shop semakin ketat. Kevindra Soemantri, pemerhati kuliner dan gaya hidup mengungkapkan, dari tahun 2014 gaya hidup mengonsumsi kopi meningkat, terutama di kota besar, seperti Jakarta. Di tahun 2014 beberapa media di Inggris mengatakan bahwa terjadi penurunan secara global untuk minuman beralkohol. Hal ini membuat kopi menjadi minuman favorit baru (Ikhsaina,2017). Gaya hidup dan budaya masyarakat Indonesia yang telah berubah ini membawa pengaruh dan dampak positif bagi para pengusaha kuliner khususnya coffee shop.

Salah satu coffee shop tersebut adalah Bloom Coffee \& Eatery. Bloom Coffee \& Eatery atau yang lebih sering disebut dengan Bloom Coffee merupakan sebuah coffee shop yang telah berdiri sejak 2017. Hingga Agustus 2020, Bloom Coffee memiliki lebih dari 6.000 followers dalam akun instagramnya (@bloomcoffeejkt). Bloom Coffee memiliki jumlah followers yang lebih banyak dari coffee shop lainnya yang memiliki lokasi berdekatan seperti Kopi Kusuma, Kedai Paris, dan WJ de Café. Dapat dikatakan bahwa Bloom Coffee lebih unggul dalam menjangkau banyak khalayak melalui instagram sebagai media promosinya. Konten yang terdapat di dalam akun ini juga tertata dengan rapi dan memiliki konsep yang menarik. Sebagai coffee shop yang masih terbilang baru, Bloom Coffee tidak kalah menarik dari coffee shop ternama lainnya. Bloom Coffee memiliki strategi digital marketing yaitu content marketing melalui media sosial instagram.

Strategi Content Marketing Untuk Membangun Brand Awareness (Studi Kasus Video Aftermovie Djakarta Warehouse Project) oleh Aprilia., et al (2019) persamaan penelitiannya adalah penelitian dilakukan untuk mengetahui Content Marketing dalam menarik konsumen, sedangkan perbedaannya terdapat di tujuan, yaitu antara Brand Awareness dengan Customer Engagement.

\section{Hipotesis Penelitian :}

$\mathrm{H}_{1}$ : Content Marketing berpengaruh secara signifikan terhadap Customer Engagement.

\section{Content Marketing}

Menurut Frost., et al (2016) Content Marketing (konten pemasaran) adalah sebuah strategi yang melibatkan pembuatan dan penerbitan konten dalam situs web dan media sosial. Semua konten online dapat dikatakan content marketing yang berkisar situs web, halaman jaringan sosial, unggahan blog sampai video, white papers, dan eBuku

\section{Customer Engagement}

Menurut K, J. Joseph and Bindal (2018) Customer Engagement adalah hubungan antara pelanggan dengan merek. Keterlibatan pelanggan dibangun dan dibangun kembali dengan setiap interaksi merek, apakah melakukan pembelian, membaca posting sosial media atau paparan apa pun mengenai merek. 


\section{Metode Penelitian}

Berdasarkan jenisnya, penelitian ini menggunakan jenis survei. Menurut Sugiyono (2015) penelitian survei dilakukan pada populasi besar maupun kecil, tetapi data yang dipelajari adalah data yang diambil dari sampel diambil dari populasi tersebut.

Metode pengumpulan data dalam penelitian ini dilakukan dengan cara memberikan kuesioner kepada 100 responden followers instagram @bloomcoffeejkt sesuai kriteria yang telah dibuat oleh peneliti, Sampel menurut Sugiyono (2015) adalah bagian dari jumlah dan karakteristik yang dimiliki oleh populasi tertentu. Teknik pengambilan sampel dalam penelitian ini adalah dengan menggunakan simple random sampling yang pengambilan anggota sampelnya dari populasi dilakukan secara acak tanpa memperhatikan strata yang ada didalam populasi itu. Sampel pada penelitian ini berupa followers akun Instagram @Bloomcoffeejkt.

\section{Hasil Temuan dan Diskusi}

Bloom coffee \& eatery merupakan sebuah coffee shop \& community space yang berdiri sejak 8 maret 2017. Berkonsep sebagai community space, Bloom di desain sebagai wadah bagi masyarakat Jelambar dan sekitarnya untuk membangun komunitas, bekerja, ataupun sekedar rehat dan bersantai.

Bloom hadir untuk menjawab kebutuhan dan keresahan masyarakat sekitar akan tempat berkumpul yang nyaman dengan harga yang terjangkau. Bloom juga kini berekspansi dengan menggarap sektor produksi dengan brand Rumah Sangrai Bloom. Berdiri sejak 2018, dan berkomitmen untuk menyediakan supply coffee beans terbaik dan konsisten untuk mengusung kemajuan industri kopi Indonesia.

\section{Identitas Responden}

Diagram 1. Jenis Kelamin Responden

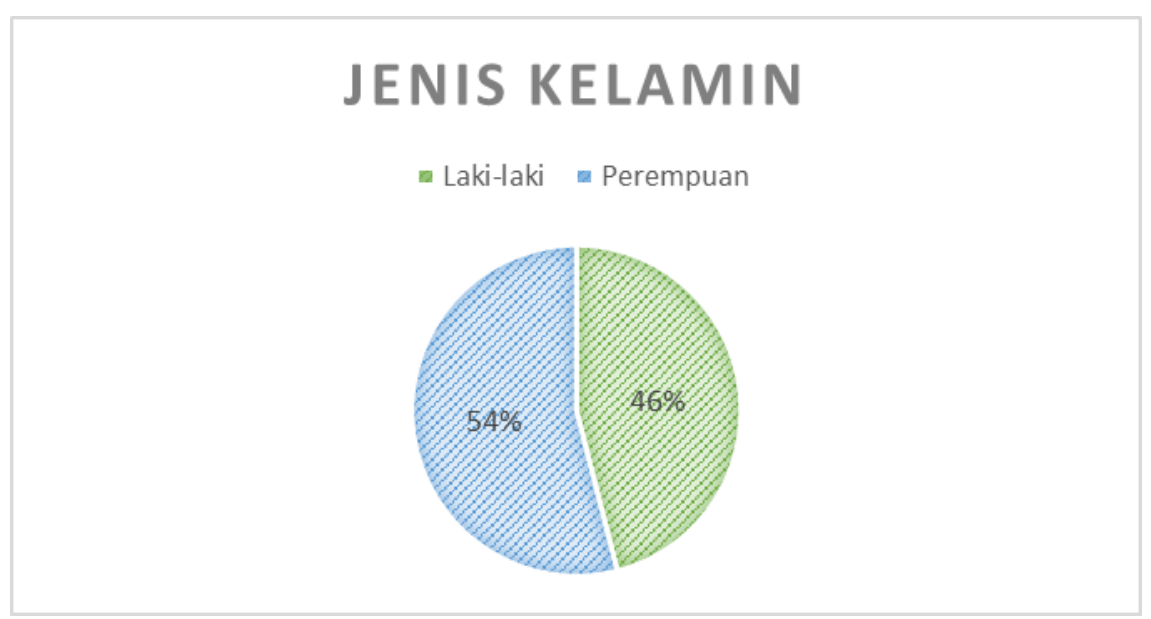

Sumber : Data dari hasil Peneliti (2020)

Berdasarkan Diagram 1 di atas, dapat diketahui bahwa sampel followers bloomcoffeejkt yang didapatkan dalam survei penelitian ini sebagian besar 
Heru Chandra Litmanen, Wulan Purnama Sari: Analisis Pengaruh Content Marketing terhadap Customer Engagement (Studi Pada Instagram @bloomcoffeejkt)

responden berjenis kelamin perempuan sebanyak 54 responden (54\%), dan 46 responden berjenis kelamin laki-laki (46\%).

Diagram 2. Usia Responden

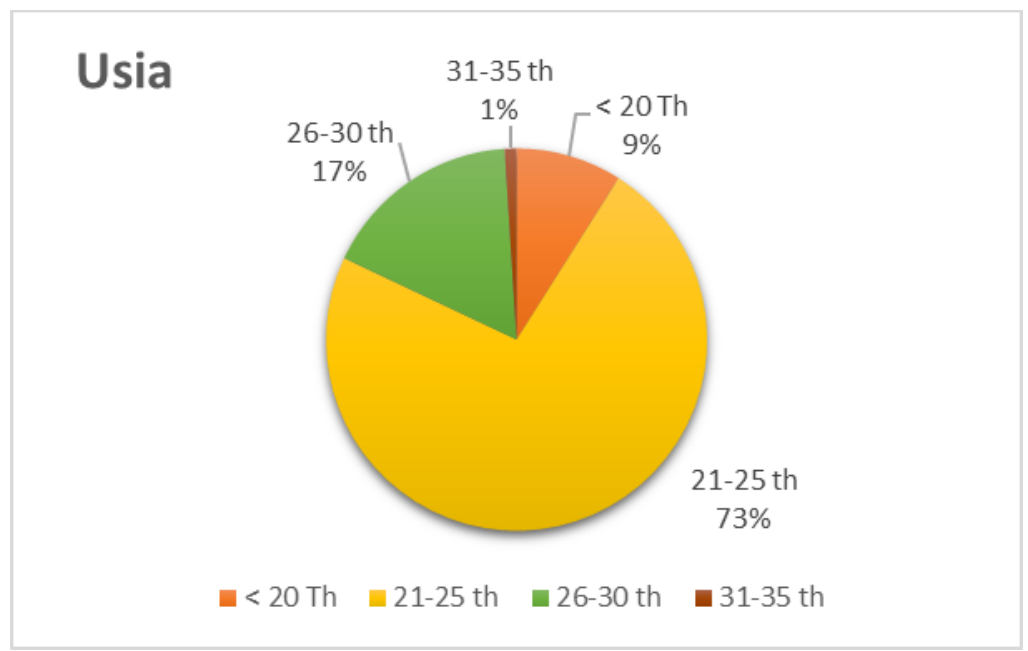

Sumber: Data dari hasil Peneliti (2020)

Berdasarkan Diagram 2 diketahui bahwa sampel followers bloomcoffeejkt mayoritas berusia 21-25 Tahun sebanyak 73 responden (73), 17 responden berusia 26-30 tahun (17\%), 9 responden berusia $<20$ tahun $(9 \%)$, dan 1 responden berusia 31-35 tahun (1\%).

\section{Uji Validitas}

Kuesioner penelitian ini terdiri dari 11 pernyataan untuk variabel $\mathrm{X}$ dan 11 pernyataan untuk variabel $\mathrm{Y}$ disebarkan peneliti kepada 100 responden, kemudian hasil perolehan data digunakan untuk melakukan uji validitas, perhitungan dilakukan menggunakan IBM SPSS Statistics 22. Berdasarkan hasil temuan yang diolah peneliti bahwa Sig. dari semua pertanyaan atau pernyataan dibawah 5\% atau 0,05 maka dapat disimpulkan bahwa instrumen-instrumen dalam Content Marketing (X) dan Customer Engagement (Y) yang diuji valid.

\section{Uji Reliabilitas}

Pengujian reliabilitas dilakukan kepada 100 responden, Cronbach's Alpha $0,835>0,6$ yang menunjukkan bahwa instrumen variabel $C M$ reliabel dan 0,895> 0,6 yang menunjukan bahwa instrumen variabel $C E$ reliabel.

\section{Uji Regresi Linear Sederhana}

Tabel 1. Hasil Uji Regresi Linear Sederhana

\begin{tabular}{|l|l|l|}
\hline \multirow{2}{*}{ Model } & \multicolumn{2}{|l|}{ Unstandardized Coefficients } \\
\cline { 2 - 3 } & $\mathrm{B}$ & Std. Error \\
\hline (Constant) & -5.778 & 2.747 \\
Content Marketing & 1.041 & .078 \\
\hline
\end{tabular}

Sumber: Hasil Uji IBM SPSS Statistics 22 
Berdasarkan data tabel 1. diatas maka persamaan regresi sebagai berikut: $\mathrm{CE}$ $=-5,778+1,041 \mathrm{CM}$. Persamaan regresi di atas menunjukkan nilai Constant sebesar $-5,778$, ini artinya jika $C M$ dianggap konstan atau bernilai 0 (nol), maka $C E$ akan naik sebesar 5,778 satuan atau 578,8\%. Koefisien regresi variabel $C M$ sebesar 1,041, hal ini artinya jika variabel $C M$ bertambah satu satuan maka variabel $C E$ akan naik sebesar 1,041 satuan atau 104,1\%, dengan catatan variabel lain dianggap konstan.

\section{Uji Koefisien Determinasi $\left(\mathbf{r}^{2}\right)$}

Tabel 2. Hasil Uji Koefisien Determinasi $\left(r^{2)}\right.$

\begin{tabular}{|l|l|l|l|l|}
\hline \multicolumn{3}{|c|}{ Model Summary } \\
\hline Model & $\mathrm{R}$ & R Square & $\begin{array}{l}\text { Adjusted R } \\
\text { Square }\end{array}$ & $\begin{array}{l}\text { Std. Error of } \\
\text { the Estimate }\end{array}$ \\
\hline 1 &, $802^{\mathrm{a}}$ &, 644 &, 640 & 3,732 \\
\hline
\end{tabular}

Sumber: Hasil Uji IBM SPSS Statistics 22

Berdasarkan tabel 2. disimpulkan bahwa nilai koefisien determinasi $\left(\mathrm{R}^{2}\right)$ adalah 0,644 . Hal ini artinya $64,4 \%$ variasi $C E$ dapat dijelaskan oleh variabel independen yang diteliti $C M$. Sedangkan sisanya 35,6\% (100\% - 64,4\%) oleh variabel lain yang tidak diteliti dalam penelitian ini.

\section{Uji T}

Tabel 3. Hasil Uji T

\begin{tabular}{|c|c|c|c|c|c|c|}
\hline \multirow{2}{*}{\multicolumn{2}{|c|}{ Model }} & \multicolumn{2}{|c|}{$\begin{array}{l}\text { Unstandardized } \\
\text { Coefficients }\end{array}$} & \multirow{2}{*}{$\begin{array}{l}\text { Standardized } \\
\text { Coefficients } \\
\text { Beta }\end{array}$} & \multirow[b]{2}{*}{$\mathrm{t}$} & \multirow[b]{2}{*}{ Sig. } \\
\hline & & B & $\begin{array}{l}\text { Std. } \\
\text { Error }\end{array}$ & & & \\
\hline \multirow[t]{2}{*}{1} & (Constant) & $-5,778$ & 2,747 & & $-2,103$ & 0,038 \\
\hline & Content Marketing & 1,041 & 0,78 & 0,802 & 13,308 & 0,000 \\
\hline
\end{tabular}

Sumber: Data diolah Peneliti (2020)

Berdasarkan tabel 3. disimpulkan variabel $C M$ memiliki nilai signifikansi 0,000 atau lebih kecil dari 0,05 sehingga dalam penelitian ini, $C E$ berpengaruh secara signifikan terhadap Customer Engagement.

\section{CM (X) terhadap CE (Y)}

a. Hipotesis

$\mathrm{H}_{1} \quad: C M(\mathrm{X})$ berpengaruh secara signifikan terhadap $C E(\mathrm{Y})$.

$\mathrm{H}_{0} \quad$ : $C M(\mathrm{X})$ tidak berpengaruh secara signifikan CE (Y).

b. Diterima atau Ditolak Hipotesis

Dasar pengambilan keputusan bahwa jika Sig. $>0,05$ maka $\mathrm{H}_{0}$ diterima sementara $\mathrm{H}_{1}$ ditolak, sedangkan jika Sig. $<0,05$ maka $\mathrm{H}_{0}$ ditolak sementra $\mathrm{H}_{1}$ diterima. Hasil pengujian hipotesis pengaruh variabel $C M$ terhadap $C E$ memberitahu bahwa variabel $C M$ berpengaruh secara signifikan terhadap $C E$. Hal ini diperlihatkan dari signifikansi $C M$ terhadap $C E$ yaitu $0,000>0,05$ dapat disimpulkan bahwa hipotesis $C M$ berpengaruh secara signifikan terhadap $C E$ atau $\mathrm{H}_{1}$ diterima.

Salah satu tolak ukur Content Marketing adalah Reader Cognition. Menurut Karr (2016) untuk menyampaikan ke audience diperlukan konten yang menarik dan 
mudah dicerna. Salah satu usaha yang diperlukan dengan memberikan interaksi visual, audio, dan kinestetik yang menarik agar mudah dijangkau oleh audience. Perusahaan juga harus dapat menyakinkan audience untuk tertarik dalam proses menjadi konsumennya. Salah satu contoh audience tertarik dengan konten yaitu dengan memberikan likes dan menyebarkan pada setiap konten. Prinsip persuasi seperti kesukaan, timbal balik, konsistensi konsumen terhadap konten ini akan meningkatkan engagement pada setiap konten. Dimensi utama dari Customer Engagement adalah attention (perhatian) mengacu pada tingkat fokus dan perhatian konsumen secara sadar maupun tidak sadar terhadap suatu konten. Penyebab utama $C M$ berpengaruh secara signifikan terhadap $C E$ karena adanya keterlibatan konsumen di setiap konten berupa visual, audio yang dibuat dengan menarik dan mudah dicernah konsumen. Sehingga konsumen akan memberikan timbal balik terhadap konten tersebut dengan memberikan likes dan membagikan konten ke kerabat masing-masing.

Dengan adanya bentuk timbal balik tersebut konsumen membantu meningkatkan Engagement dalam setiap konten-konten. Penerapan salah satu indikator dalam membuat konten yang menarik dan mudah dicerna konsumen yang dilakukan oleh Bloomcoffeejkt dapat meningkatkan engagement. Hal ini didukung oleh penelitian Limandono (2017) bahwa $C M$ berpengaruh secara signifikan terhadap $C E$.

\section{Kesimpulan}

Berdasarkan data yang sudah diserahkan dan pengujian yang sudah dilakukan kepada permasalahan dengan memakai metode analisi regresi sederhana, maka diambil kesimpulan bahwa Content Marketing yang diterapkan di@Bloomcoffeejkt berpengaruh secara signifikan terhadap Customer Engagement. Karena, @Bloomcoffeejkt berhasil menerapkan Reader Cognition dan Persuasion yang berfokus membuat konten yang menarik dan mudah dicerna untuk mengikat konsumen. Dimana ketertarikan konsumen akan menimbulkan timbal balik atau feedback untuk konten yang bertujuan meningkatkan customer engagement.

Beberapa hal yang dilakukan konsumen agar konten dari@Bloomcoffeejkt menarik yaitu dengan memberikan Attention (perhatian) dapat berupa likes, share ke teman atau kerabat lainnya untuk dijadikan dasar dari Costumer Engagement itu sendiri.

\section{Ucapan Terima Kasih}

Penulis mengucapkan terima kasih kepada responden yang sudah bersedia membantu mengisi kuesioner. Tidak lupa kepada keluarga dan teman-teman yang sudah mendukung, memberikan waktu serta pemikiran untuk membantu penulis dalam menyelesaikan penyusunan penelitian ini.

\section{Daftar Pustaka}

Aprilia, L., CLimadnodnoandraningrum, D. A., \& Pandrianto, N. (2019). Strategi Content Marketing untuk Membangun Brand Awareness (Studi kasus Video Aftermovie Djakarta Warehouse Project). Prologia Vol. 3 (1), 177-181 https://journal.untar.ac.id/index.php/prologia/article/view/6236 
Bindal, M., \& Jacob, J. K. (2018). The Impact of Brand Post Strategy And Social Media Engagement On Customer Loyalty. International Journal of Management Studies, 48-55.

Frost, Raymond, Judy, \& Strauss. (2016). E-Marketing. New York: Routledge.

Ikhsania, A. A. (2017, 11 09). lifestyle. Retrieved from okezone: https://lifestyle.okezone.com/read/2017/11/09/298/1811342/alasan-konsumsikopi-jadi-tren-gaya-hidup-masyarakat-urban

Karr, D. (2016). How To Map Your Content To Unpredictable Customer Journeys. Meltwater Outside Insight.

Limandono, J. (2017). Pengaruh Content Marketing dan Event Marketing Terhadap Customer Engagement dengan Social Media Marketing Sebagai Variabel Moderasi di Pakuwon City. Jurnal Strategi Pemasaran, 1-11.

Sugiyono. (2015). Metode Penelitian Kuantitatif, Kualitatif, dan R\&D. Bandung: Alfabeta,CV. 